\title{
Synthesis and Thermal Properties of Fully Aromatic Polysilarylenesiloxanes
}

\author{
Hitoshi Ito, ${ }^{1, \dagger}$ Eiichi AkiYAma, ${ }^{2}$ Yu Nagase, ${ }^{3}$ Akiko YAmamoto $^{3}$ and Saburo Fukui ${ }^{3}$ \\ ${ }^{1}$ Applied Chemistry Lab., Ebara Research Co., Ltd., 4-2-1 Honfujisawa, Fujisawa 251-8502, Japan \\ ${ }^{2}$ Sagami Chemical Research Center, 2743-1, Hayakawa, Ayase 251-1193, Japan \\ ${ }^{3}$ Department of Applied Chemistry, School of Engineering, Tokai University, \\ 1117 Kitakaname, Hiratsuka 259-1292, Japan
}

(Received July 5, 2005; Accepted September 7, 2005; Published February 15, 2006)

\begin{abstract}
A new type of fully aromatic polysilarylenesiloxanes showing high $T_{\mathrm{g}}$ was synthesized via the solution polymerization from the bis(diphenylhydroxysilyl)arylene monomers. And the thermal properties of these monomers and polymers were investigated by using differential scanning calorimetry (DSC), and thermogravimetry analysis (TGA). The monomers containing the diphenylsilanol group showed higher melting temperatures and thermal degradation temperatures than those of the monomers containing the dimethylsilanol group. The obtained fully aromatic polysilarylenesiloxanes were insoluble powders, and showed no weight loss in air below $500^{\circ} \mathrm{C}$. No glass transition was detected according to the DSC measurements, whereas 3a and $\mathbf{3 b}$ showed melting points at 323 and $391{ }^{\circ} \mathbf{C}$, respectively. However, $\mathbf{3 b}$ held solid-state at melting point. It would be caused by a cross-linking reaction occurring with melting simultaneously. It was found that these were the thermally stable polymer-solids consisted of the organosiloxane polymers. [DOI 10.1295/polymj.38.109]

KEY WORDS Polysilarylenesiloxanes / Thermal Stability / Solution Polymerization / Glass Transition / High-temperature Coatings /
\end{abstract}

Organosiloxane polymers, especially polydimethylsiloxane (PDMS) and their derivatives, are practically important materials as elastomers, ${ }^{1-3}$ lubricating oils and electrical insulations based on their mechanical, chemical and physical properties. ${ }^{4-6}$ In addition, PDMS derivatives, polymethacrylates having bulky substituents like a tris(trimethylsiloxy)silyl group, poly(1-trimethylsilylpropyne) and so on, have been studied as pervaporation membranes, oxygen-enriching membranes and selectively transporting membranes in the fields of chemical and medicinal chemistry because of their high permeability of gases and organic components. ${ }^{7}$ On the other hand, polysilarylenesiloxanes $^{8,9}$ and their copolymers ${ }^{9-24}$ have been studied as high temperature elastomers whose thermal degradation temperatures $\left(T_{\mathrm{d}}\right)$ were greatly higher than those of PDMS.

Poly(tetramethyl-p-silphenylene)siloxane (TMPS) of a typical polysilarylenesiloxane was synthesized by Merker et al. ${ }^{8}$ And their thermal properties were investigated by Okui et al.,${ }^{9}$ Ikeda et al. ${ }^{10}$ and Funt et al. ${ }^{11}$ According to their reports, TMPS shows a glass transition temperature $\left(T_{\mathrm{g}}\right)$ of $-20^{\circ} \mathrm{C}$, a melting point $\left(T_{\mathrm{m}}\right)$ of $135^{\circ} \mathrm{C}$ and a $T_{\mathrm{d}}$ of $370-390^{\circ} \mathrm{C}$. TMPS/ PDMS copolymers were synthesized and their thermal degradation behavior was reported. ${ }^{9-15}$ We had also reported their preparations and thermal properties. ${ }^{10,16-19}$ These copolymers have two major transi- tions at around $-120^{\circ} \mathrm{C}$ corresponding to the $T_{\mathrm{g}}$ of PDMS moiety and at $-10^{\circ} \mathrm{C}$ related to the amorphous TMPS moiety. ${ }^{19}$ And their $T_{\mathrm{d}}$ was estimated at $300{ }^{\circ} \mathrm{C}$, lower than that of TMPS homopolymer. ${ }^{10}$ Furthermore, arylene-modified siloxanes were synthesized and their thermal properties were studied..$^{12,20-24}$ Their thermal properties were similar to those of the TMPS/ PDMS copolymers.

For these TMPS-containing polymers, the common characteristics of the high $T_{\mathrm{d}}$ and the low $T_{\mathrm{g}}$, which result from their flexible tetramethyldisiloxane units in main chain, are desirable properties as elastomers, so that these polymers are waxy or gum like materials at high temperature. Therefore, polysilarylenesiloxanes and their copolymers have been used as nothing but elastomers, although their interesting and unique properties have been expected from these kinds of organosiloxane materials.

If a new type of polysilarylenesiloxane with a high $T_{\mathrm{g}}$ is obtained, it is possible that the polysilarylenesiloxane is applied to various fields, such as a high-temperature coating, a functionalized self-standing membrane, a low dielectric constant insulation material in semiconductor devices, and a stationary phase for gas chromatography. But such polysilarylenesiloxane showing a sufficiently high $T_{\mathrm{g}}$ has never been reported.

Recently, Kawakami et al., ${ }^{25-27}$ reported the polymer derived from cardo-type 9,9'-bis[4-(dimethyl-

${ }^{\dagger}$ To whom correspondence should be addressed (Tel: +81-466-83-7022, Fax: +81-466-81-7220, E-mail: itoh.hitoshi@er.ebara.com). 


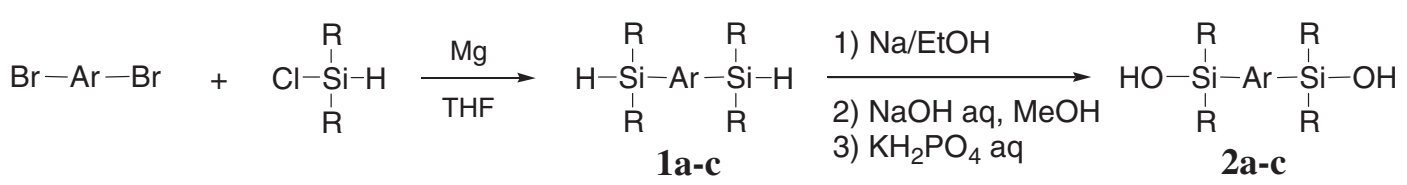

\begin{tabular}{ccc} 
Code & $-\mathrm{R}$ & $-\mathrm{Ar}-$ \\
\hline $\mathbf{a}$ & - & \\
$\mathbf{b}$ & - & -
\end{tabular}

Scheme 1. Synthesis of monomers.

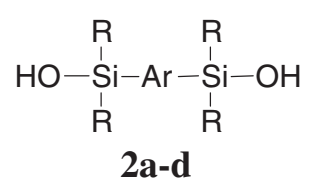
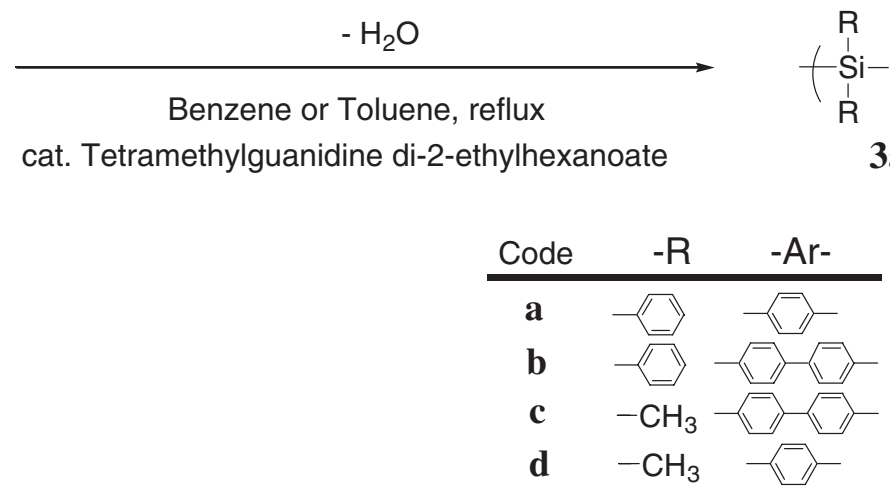

Scheme 2. Polymerizations of the disilanol monomers.

silyl)phenyl]fluorene using a new method of the catalytic cross-dehydrocoupling polymerization, and that this polymer exhibited high $T_{\mathrm{g}}$ of $161^{\circ} \mathrm{C}$ and good thermal mechanical properties. ${ }^{27}$ However, the higher thermal and mechanical stabilities are demanded for high temperature-resistant insulating materials in semiconductor devices and other applications. ${ }^{28-30} \mathrm{We}$ tried to another approach to synthesize polysilarylenesiloxane with a high $T_{\mathrm{g}}$, that is, introducing a tetraphenyldisiloxane unit instead of a tetramethyldisiloxane unit. PDMS and polydiphenylsiloxane (PDPS) show $-123^{\circ} \mathrm{C}$ of a $T_{\mathrm{g}}$ and $265^{\circ} \mathrm{C}$ of a $T_{\mathrm{m}}$, respectively, according to the literature. ${ }^{9,31}$ Therefore, the superior thermal mechanical properties will be expected of the poly(tetraphenyl- $p$-silarylene)siloxane compared with the corresponding poly(tetramethyl- $p$-silarylene)siloxanes. In the literature,${ }^{20}$ copolymers derived from 1,4-bis(diphenylhydroxysilyl)benzene and dimethylsiloxane oligomer were synthesized, but unfortunately their thermal degradation behavior had not been reported. Furthermore, the thermal properties of the poly(tetraphenyl- $p$-silarylene)siloxane have never been investigated. On the other hand, the syntheses of the some kinds of $p$-bis(hydroxydiphenylsilyl)arylene monomers were reported in the literature, ${ }^{32-34}$ in which their $T_{\mathrm{m}}$ 's were described, but their thermal degradation properties had not been revealed. The thermal properties of the monomers would give an important information to design the functionality of the polymers derived from them.

In this paper, the thermal properties for the four kinds of disilanol monomers (2a-d in Scheme 1) which were synthesized according to the literature, ${ }^{32-34}$ except for commercially available $2 \mathbf{d}$ of 1,4-bis(hydroxydimethylsilyl)benzene, were investigated in detail by using differential scanning calorimetry (DSC), and thermogravimetry analysis (TGA). Then, two kinds of poly(tetraphenyl- $p$-silarylene)siloxanes $(\mathbf{3 a}, \mathbf{3 b})$ introducing $p$-phenylene and $p, p^{\prime}-$ biphenylene moieties were synthesized via the solution polymerization from the arylenedisilanol monomers of $\mathbf{2 a}, \mathbf{2} \mathbf{b}$. The corresponding poly(tetramethyl$p$-silarylene)siloxanes were also prepared $(\mathbf{3 c}, \mathbf{3 d})$ in the similar procedure (3a-d in Scheme 2). The thermal properties of these polymers were investigated, and compared with those of the monomers. From these results, the influence of chemical structures of the main and side chains on the thermal stability of the corresponding polymers will be discussed.

\section{EXPERIMENTAL}

\section{Materials}

Tetarahydrofuran (THF) and toluene were dried by the distillation over sodium. 1,4-Dibromobenzene, 4,4'-dibromobiphenyl, dimethylchlorosilane and di- 
phenylchlorosilane were purchased from Aldrich Chemicals Co. Inc., and used without any purifications. Magnesium savings and sodium were provided from Kishida Chemicals Co. Ltd. and Wako Pure Chemicals Ind. Ltd., respectively. The three monomers $\mathbf{2 a}, \mathbf{2 b}$ and $\mathbf{2 c}$ were synthesized according to the literature (Scheme 1). ${ }^{32-34} \mathbf{2 d}$ was purchased from Chisso Corp., and purified by recrystallization from a mixture solution of THF and $n$-hexane before use. Tetramethylguanidine di-2-ethylhexanoate was prepared by mixing tetamethylguanidine and 2-ethylhexanoic acid in 1:2 molar ratio for several days.

\section{Characterizations}

${ }^{1} \mathrm{H}$ NMR spectra were measured on Bruker BioSpin AVANCE DRX 400 Spectrometer (400 MHz). IR spectra were measured with PerkinElmer PARAGON FT-IR. Gel permeation chromatography (GPC) was carried out to determine the number-average and weight-average molecular weights with Tosoh HLC$802 \mathrm{~A}$ instrument by using THF as an eluent, equipped with four columns of TSK gels, $\mathrm{G}^{2} 000 \mathrm{H}_{6}, \mathrm{G} 4000 \mathrm{H}_{6}$, $\mathrm{G} 3000 \mathrm{H}_{6}$ and $\mathrm{G}_{2000 \mathrm{H}_{6}}$. Standard polystyrenes were used for calibration. X-Ray diffraction (XRD) patterns by the powder method were collected on a RIGAKU RINT 2000 Diffractometer using $\mathrm{CuK} \alpha$ radiation. 3a and $\mathbf{3 b}$ were annealed for $1 \mathrm{~h}$ at $160^{\circ} \mathrm{C}$. 3c and $\mathbf{3 d}$ were also annealed at $T_{\mathrm{g}}$ and $T_{\mathrm{m}}$, respectively, before measurements.

\section{Preparations of Monomers}

1,4-Bis(diphenylsilyl)benzene (1a). A solution of diphenylchlorosilane $(5.3 \mathrm{~mL}, 27 \mathrm{mmol})$ in $10 \mathrm{~mL}$ of THF was added dropwise to magnesium savings $(0.88 \mathrm{~g}, 37 \mathrm{mmol})$ under an argon atmosphere. Then 1,4-dibromobenzene $(2.1 \mathrm{~g}, 9.0 \mathrm{mmol})$ in $10 \mathrm{~mL}$ of THF was added slowly dropwise to the mixture. After moderately refluxed for $17 \mathrm{~h}, 1 \mathrm{~mL}$ of water was added to the mixture. The crude products were extracted with diethyl ether and washed with water. The organic layer was dried over anhydrous $\mathrm{Na}_{2} \mathrm{SO}_{4}$. After the solvents were evaporated, the residue was purified by column chromatography on silica gel with $n$-hexane as an eluent to afford $1.9 \mathrm{~g}$ of $\mathbf{1 a}$ as a colorless solid. Yield: $48 \% .{ }^{1} \mathrm{H}$ NMR, $\delta$ (ppm, $\mathrm{CDCl}_{3}, 400 \mathrm{MHz}$ ): $5.46(2 \mathrm{H}, \mathrm{s}), 7.38(8 \mathrm{H}, \mathrm{m}), 7.39(4 \mathrm{H}, \mathrm{m}), 7.57(8 \mathrm{H}, \mathrm{m})$, $7.58(4 \mathrm{H}, \mathrm{s})$. IR, $v\left(\mathrm{~cm}^{-1}, \mathrm{KBr}\right.$ disk): $3041(\mathrm{w}), 3004$ (w), 2110 (m, Si-H st), 1587 (w), 1483 (w), 1424 (s), 1133 (w), 1115 (m), 827 (m), 798 (s), 742 (s), 728 (s), 536 (s), 503 (s).

1,4-Bis(hydroxydiphenylsilyl)benzene (2a). 1a (1.5 $\mathrm{g}, 3.4 \mathrm{mmol})$ in $\mathrm{THF} /$ ethanol $(30 \mathrm{~mL} / 50 \mathrm{~mL})$ was added dropwise to $0.7 \mathrm{~g}$ of metal sodium soaked in $42 \mathrm{~mL}$ of anhydrous ethanol. After ceasing to generate hydrogen gas, $\mathrm{NaOH}(0.70 \mathrm{~g})$ solution in methanol/ water $(7.0 \mathrm{~mL} / 0.70 \mathrm{~mL})$ was poured into the mixture, stirring for $30 \mathrm{~min} .7 .0 \mathrm{~mL}$ of $\mathrm{NaOH}(0.70 \mathrm{~g})$ aqua were added to the mixture, stirring for $30 \mathrm{~min}$. $\mathrm{KH}_{2} \mathrm{PO}_{4}(11 \mathrm{~g})$ aqua with excess ice was added to the mixture. Then, the precipitate was filtered, and washed with water. The mixture was purified by recrystallization from a chloroform solution to afford $1.3 \mathrm{~g}$ of $\mathbf{2 a}$ as a colorless solid. Yield: $80 \% .{ }^{1} \mathrm{H}$ NMR, $\delta\left(\mathrm{ppm}, \mathrm{CDCl}_{3}, 400 \mathrm{MHz}\right): 7.39(4 \mathrm{H}, \mathrm{m}), 7.41(8 \mathrm{H}$, $\mathrm{m}), 7.63(8 \mathrm{H}, \mathrm{m}), 7.65(4 \mathrm{H}, \mathrm{s}) . \mathrm{IR}, v\left(\mathrm{~cm}^{-1}, \mathrm{KBr}\right.$ disk): 3208 (s, SiO-H st), 3044 (m), 3007 (m), 1585 (m), 1481 (m), 1425 (s), 1373 (m), 1138 (s), 1119, (s) $862(\mathrm{~s}), 836(\mathrm{~s}), 758(\mathrm{~m}), 739(\mathrm{~m}), 713$ (s), 698 (s), 545 (s).

4,4'-Bis(diphenylsilyl)biphenyl (1b). $\quad \mathbf{1 b}$ was prepared from 4,4'-dibromobiphenyl in the same manners as 1a. Yield: $52 \%$. ${ }^{1} \mathrm{H}$ NMR, $\delta$ (ppm, $\mathrm{CDCl}_{3}, 400$ $\mathrm{MHz}): 5.55(2 \mathrm{H}, \mathrm{s}), 7.43(8 \mathrm{H}, \mathrm{m}), 7.44(4 \mathrm{H}, \mathrm{m}), 7.64$ $(4 \mathrm{H}, \mathrm{m}), 7.65(8 \mathrm{H}, \mathrm{m}), 7.70(4 \mathrm{H}, \mathrm{m}) . \mathrm{IR}, v\left(\mathrm{~cm}^{-1}, \mathrm{KBr}\right.$ disk): 3070 (m), 3003 (m), 2125 (s, Si-H st), 1594 (w), 1428 (s), 1115 (s), 812 (s), 787 (s), 735 (m), 694 (s).

4,4'-Bis(hydroxydiphenylsilyl)biphenyl (2b). $\quad \mathbf{2 b}$ was prepared in the same manners as $\mathbf{2 a}$. Yield: $36 \%$. ${ }^{1} \mathrm{H}$ NMR, $\delta$ (ppm, $\left.\mathrm{CDCl}_{3}, 400 \mathrm{MHz}\right): 7.41(8 \mathrm{H}, \mathrm{m})$, $7.42(4 \mathrm{H}, \mathrm{m}), 7.62(4 \mathrm{H}, \mathrm{m}), 7.66(8 \mathrm{H}, \mathrm{m}), 7.71(4 \mathrm{H}$, m). IR, $v\left(\mathrm{~cm}^{-1}, \mathrm{KBr}\right.$ disk): 3292 (s, SiO-H st), 3062 (w), 3018 (w), 1594 (w), 1424 (m), 1119 (s), 1001 (s), $857(\mathrm{~m}), 831$ (m), $805(\mathrm{~m}), 706(\mathrm{~s}), 507$ (s).

4,4'-Bis(dimethylsilyl)biphenyl (1c). 1c was prepared from 4,4'-dibromobiphenyl and dimethylchlorosilane in the same manners as 1a. Yield: $61 \%$. ${ }^{1} \mathrm{H}$ NMR, $\delta$ (ppm, $\left.\mathrm{CDCl}_{3}, 400 \mathrm{MHz}\right): 0.38(12 \mathrm{H}, \mathrm{d}$, $J=4.0 \mathrm{~Hz}), 4.46(2 \mathrm{H}, \mathrm{m}), 7.60(4 \mathrm{H}, \mathrm{d}, J=8.4 \mathrm{~Hz})$, $7.63(4 \mathrm{H}, \mathrm{d}, J=8.4 \mathrm{~Hz})$. IR, $v\left(\mathrm{~cm}^{-1}, \mathrm{KBr}\right.$ disk): 2962 (w), 2119 (m, Si-H st), 1595 (w), 1249 (m), 1117 (m), 876 (s), 836 (m), 808 (m), 764 (m), 699 (m).

4,4'-Bis(dimethylhydroxysilyl)biphenyl (2c). $2 c$ was prepared in the same manners as 2a. Yield: $27 \%$. ${ }^{1} \mathrm{H}$ NMR, $\delta\left(\mathrm{ppm}, \mathrm{CDCl}_{3}, 400 \mathrm{MHz}\right): 0.45(12 \mathrm{H}, \mathrm{d}$, $J=4.0 \mathrm{~Hz}), 7.61(4 \mathrm{H}, \mathrm{d}, J=8.0 \mathrm{~Hz}), 7.67(4 \mathrm{H}, \mathrm{d}, J=$ $8.0 \mathrm{~Hz}) . \mathrm{IR}, v\left(\mathrm{~cm}^{-1}, \mathrm{KBr}\right.$ disk): $3262(\mathrm{~s}, \mathrm{SiO}-\mathrm{H} s t)$, 3062 (m), 3016 (m), 2961 (m), 1593 (w), 1383 (w), 1254 (s), 1120 (s), 1056 (w, br), 1003 (m), 875 (s), 826 (s), 783 (s), 699 (s), 645 (m), 512 (m).

\section{Polymerizations}

The polymers were obtained via the solution polymerization according to the literature, ${ }^{19}$ except for $\mathbf{3} \mathbf{b}^{\prime}$ which was obtained by heating $\mathbf{3 b}$ at $180^{\circ} \mathrm{C}$ for $1 \mathrm{~h}$ in air flow.

Each monomer $(1.0 \mathrm{~g})$ of $\mathbf{2 d}$ and three kinds of the synthesized monomers $(\mathbf{2 a - c})$ was refluxed for 24 $48 \mathrm{~h}$ in benzene or toluene $(5.0 \mathrm{~mL})$, respectively, in the presence of a few drops of tetramethylguanidine di-2-ethylhexanoate as a catalyst using an azeotropic 
H. ITO et al.

Table I. Conditions and results of polymerizations

\begin{tabular}{ccccccc}
\hline Polymer & $\begin{array}{c}\text { Temp. } \\
\left({ }^{\circ} \mathrm{C}\right)\end{array}$ & $\begin{array}{c}\text { Time } \\
(\mathrm{h})\end{array}$ & Solvent & $\begin{array}{c}\text { Yield } \\
(\%)\end{array}$ & $M_{\mathrm{n}} \cdot 10^{-4 \mathrm{c}}$ & $M_{\mathrm{w}} / M_{\mathrm{n}}{ }^{\mathrm{c}}$ \\
\hline $\mathbf{3 a}$ & 120 & 48 & toluene & $10^{\mathrm{b}}$ & - & - \\
$\mathbf{3 b}$ & 120 & 24 & toluene & $55^{\mathrm{b}}$ & - & - \\
$\mathbf{3 b ^ { \prime \mathbf { a } }}$ & 180 & 1.0 & - & - & - & - \\
$\mathbf{3 c}$ & 120 & 24 & toluene & 68 & 2.4 & 1.6 \\
$\mathbf{3 d}$ & 80 & 24 & benzene & 80 & 4.5 & 1.5 \\
\hline
\end{tabular}

${ }^{\mathrm{a}}$ Obtained by heating $\mathbf{3 b}$ at $180{ }^{\circ} \mathrm{C}$ for $1 \mathrm{~h}$ in air flow. ${ }^{\mathrm{b}}$ Filtered precipitation after polymerization. ${ }^{\mathrm{c}} M_{\mathrm{n}}$ and $M_{\mathrm{w}}$ are the number-average molecular weight and weight-average molecular weight, respectively.

Table II. Thermal properties of the monomers and the polymers

\begin{tabular}{|c|c|c|c|c|c|c|c|c|}
\hline Monomers & $\begin{array}{l}T_{\mathrm{m}}{ }^{\mathrm{a}} \\
\left({ }^{\circ} \mathrm{C}\right)\end{array}$ & $\begin{array}{c}\Delta H_{\mathrm{m}}^{\mathrm{b}} \\
\left(\mathrm{J} \cdot \mathrm{g}^{-1}\right)\end{array}$ & $\begin{array}{l}T_{\mathrm{d} 5}{ }^{\mathrm{c}} \\
\left({ }^{\circ} \mathrm{C}\right)\end{array}$ & Polymers & $\begin{array}{c}T_{\mathrm{m}} \\
\left({ }^{\circ} \mathrm{C}\right)\end{array}$ & $\begin{array}{c}\Delta H_{\mathrm{m}}^{\mathrm{b}} \\
\left(\mathrm{J} \cdot \mathrm{g}^{-1}\right)\end{array}$ & $\begin{array}{c}T_{\mathrm{g}}^{\mathrm{d}} \\
\left({ }^{\circ} \mathrm{C}\right)\end{array}$ & $\begin{array}{l}T_{\mathrm{d} 5}{ }^{\mathrm{c}} \\
\left({ }^{\circ} \mathrm{C}\right)\end{array}$ \\
\hline $2 a$ & 227 & -105 & 303 & $3 a$ & $323^{f}$ & -1.59 & n.d. ${ }^{g}$ & 539 \\
\hline \multirow[t]{2}{*}{$2 b$} & 191 & -142 & 264 & $3 b$ & $391^{\mathrm{a}}$ & -14.1 & n.d. ${ }^{g}$ & 500 \\
\hline & & & & $3 \mathbf{b}^{\prime e}$ & $391^{\mathrm{a}}$ & -14.1 & n.d. ${ }^{g}$ & 540 \\
\hline $2 c$ & 178 & -78.7 & 202 & $3 c$ & - & - & 67 & 517 \\
\hline 2d & 136 & -131 & 165 & 3d & $136^{\mathrm{f}}$ & -32.7 & n.d.g & 411 \\
\hline
\end{tabular}

${ }^{\mathrm{a}}$ Melting temperature determined by DSC on the first heating scan. ${ }^{\mathrm{b}}$ The enthalpy change at $T_{\mathrm{m}} \cdot{ }^{\mathrm{c}} \mathrm{The}$ temperature of the $5 \mathrm{wt} \%$ weight loss determined from a TG curve. ${ }^{\mathrm{d}}$ Glass transition temperature determined by DSC on the second heating scan. ${ }^{\mathrm{e}}$ Obtained by heating $\mathbf{3 b}$ at $180{ }^{\circ} \mathrm{C}$ for $1 \mathrm{~h}$ in air flow. ${ }^{\mathrm{f}}$ Determined by DSC on the second heating scan. ${ }^{\mathrm{g}}$ Not detected.

trap to remove water. The mixture was poured into an excess amount of methanol to purify the obtained polymer. $\mathbf{3 a}$ and $\mathbf{3 b}$ were insoluble powders to common solvents.

3a: IR, $v$ ( $\mathrm{cm}^{-1}, \mathrm{KBr}$ disk): 3048 (m), 3001 (m), 1590 (w), $1486(\mathrm{w}), 1428(\mathrm{~s}), 1373(\mathrm{w}), 1136(\mathrm{~s}), 1118,(\mathrm{~s})$ 1069 (s, br, Si-O-Si), 740 (w), 713 (s), 696 (s), 534 (s). 3b: IR, $v\left(\mathrm{~cm}^{-1}, \mathrm{KBr}\right.$ disk): 3069 (m), 3018 (m), 1597 (m), 1428 (s), 1119 (s), 1069 (s, br, Si-O-Si), 999 (s), 811 (s), 710 (s), 516 (s). 3b': IR, $v\left(\mathrm{~cm}^{-1}\right.$, $\mathrm{KBr}$ disk): 3069 (m), 3018 (m), 1596 (m), 1428 (s), 1119 (s), 1059 (s, br, Si-O-Si), 998 (s), 810 (s), 710 (s), 516 (s). 3c: ${ }^{1} \mathrm{H}$ NMR, $\delta$ (ppm, $\mathrm{CDCl}_{3}, 400 \mathrm{MHz}$ ): $0.38(12 \mathrm{H}, \mathrm{s}), 7.59(4 \mathrm{H}, \mathrm{d}, J=8.4 \mathrm{~Hz}), 7.63(4 \mathrm{H}, \mathrm{d}$, $J=8.4 \mathrm{~Hz})$. IR, $v\left(\mathrm{~cm}^{-1}, \mathrm{KBr}\right.$ disk): 3067 (w), 3016 (w), $2956(\mathrm{w}), 1597$ (w), 1256 (m), 1120 (s), 1056 (s), 1002 (m), 829 (s), 786 (s), 701 (m), 511 (w). 3d: ${ }^{1} \mathrm{H}$ NMR, $\delta$ (ppm, $\left.\mathrm{CDCl}_{3}, 400 \mathrm{MHz}\right): 0.33(12 \mathrm{H}, \mathrm{m})$, 7.56 (4H, s). IR, $v$ ( $\mathrm{cm}^{-1}, \mathrm{KBr}$ disk): 3041 (m), 2952 (m), 1406 (m), 1252 (s), 1137 (s), 1067 (w), 1016 (m), $828(\mathrm{~s}), 783$ (s), 503 (m), 466 (m).

\section{Thermal Analyses}

TGA was performed by using a Shimadzu DTG $60 \mathrm{~A}$ at a heating rate of $10^{\circ} \mathrm{C} \mathrm{min}^{-1}$ with an air flow rate of $50 \mathrm{~mL} \mathrm{~min}^{-1}$ in order to investigate the thermal degradation behavior. DSC was conducted by using a SII DSC6200 at a heating rate of $10{ }^{\circ} \mathrm{C} \mathrm{min}^{-1}$ with nitrogen flow rate of $50 \mathrm{~mL} \mathrm{~min}^{-1}$ in order to determine $T_{\mathrm{g}}$ and/or $T_{\mathrm{m}}$.

\section{RESULTS AND DISCUSSION}

\section{Polymerizations}

The conditions and the results for the polymerizations of the arylenedisilanol monomers are listed in Table I. 3a and 3b were precipitated in the polymerization solution, and obtained as insoluble powder to common solvents such as methanol, acetone, $N, N$ dimethylformamide, chloroform, dichloromethane, $n$ hexane, and THF. On the other hand, $\mathbf{3 c}$ and $\mathbf{3 d}$ were obtained as soluble polymers whose number-average molecular weights were $2-5 \times 10^{4}$. The introduction of tetraphenyldisiloxane units drastically reduced the solubility of polymers.

In IR spectra of polymers, the absorption peak at $3200 \mathrm{~cm}^{-1}$ arising from the silanol $\mathrm{O}-\mathrm{H}$ stretching vibration in the monomer $\mathbf{2}$ disappeared after polymerization, and anew the distinctive and broad absorption peak near at $1060 \mathrm{~cm}^{-1}$ arising from the $\mathrm{Si}-\mathrm{O}-\mathrm{Si}$ bond was observed. From these results, it was considered that the condensation reactions occurred, and that precipitate generated in polymerization solution was identified as polymer $\mathbf{3}$.

\section{Thermal Properties of Monomers}

The $T_{\mathrm{m}}$ 's of the monomers estimated from DSC measurements are listed in Table II. All monomers showed the melting point, and these $T_{\mathrm{m}}$ 's agreed with the literature. ${ }^{32-34}$ The $T_{\mathrm{m}}$ 's of $\mathbf{2 a}$ and $\mathbf{2 b}$ containing 


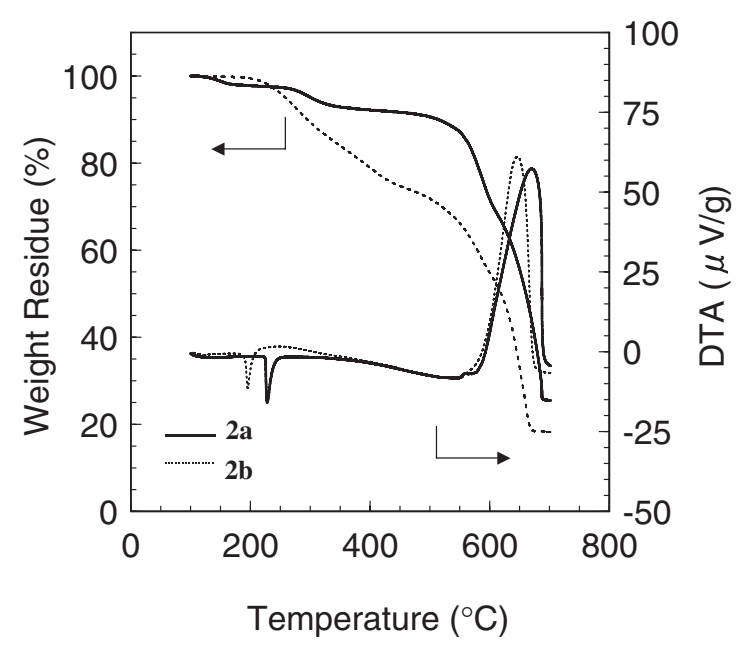

Figure 1. TG and DTA curves of $\mathbf{2 a}$ and $\mathbf{2 b}$ at a heating rate of $10^{\circ} \mathrm{C} \mathrm{min}^{-1}$ under air flow.

diphenylsilanol moiety were higher than those of $\mathbf{2 c}$ and $\mathbf{2 d}$ containing dimethylsilanol moiety. And 2a exhibited the highest $T_{\mathrm{m}}$ among these monomers. After cooling from isotropic liquid, the endothermic peak of each monomer never reappeared, and became an ambiguous one at the second heating process, except for 2d. H. N. Beck et al. had also described these phenomena, ${ }^{32}$ and pointed out that condensation of silanols occurred during prolonged heating. That is, it was suggested that these monomers polymerized by heating at slightly higher temperature than the $T_{\mathrm{m}}$.

From the TG curve of 2a in Figure 1, the four steps of weight loss behavior was observed at 140, 300, 560 and $670{ }^{\circ} \mathrm{C}$. The first small step would be derived from the removing of absorbed water. The second step starting from $270^{\circ} \mathrm{C}$, which was a little higher temperature than the $T_{\mathrm{m}}$ of $\mathbf{2 a}$, must be caused by the condensation between monomers as mentioned above. The third step and the fourth major step corresponded to a broad and slight endothermic peak and a large exothermic peak of DTA curve, respectively. Probably, the former is the partial cleavage reaction of side-chain phenyl group, and the later is an oxidative degradation of the residue.

$\mathbf{2 b}$ was a different behavior from $\mathbf{2 a}$, and exhibited a decrease of weight above the $T_{\mathrm{m}}$ in temperature region of 200 to $400{ }^{\circ} \mathrm{C}$ ( $-25 \mathrm{wt} \%$ loss). In addition, weight loss of two steps at 550 and $640{ }^{\circ} \mathrm{C}$ were also observed, were the similar degradation behavior to the case of 2a. In order to investigate the first weight loss process in the range of $200-400{ }^{\circ} \mathrm{C}$, the IR spectrum of $\mathbf{2 b}$ treated at $270{ }^{\circ} \mathrm{C}$ for $1 \mathrm{~h}$ was measured, which suggested the formation of siloxane bond based on the condensation. Unfortunately, this large weight loss could not be explained by only the condensation between the silanol groups.

The $T_{\mathrm{m}}$ and the $T_{\mathrm{d} 5}$ of each monomer are listed in

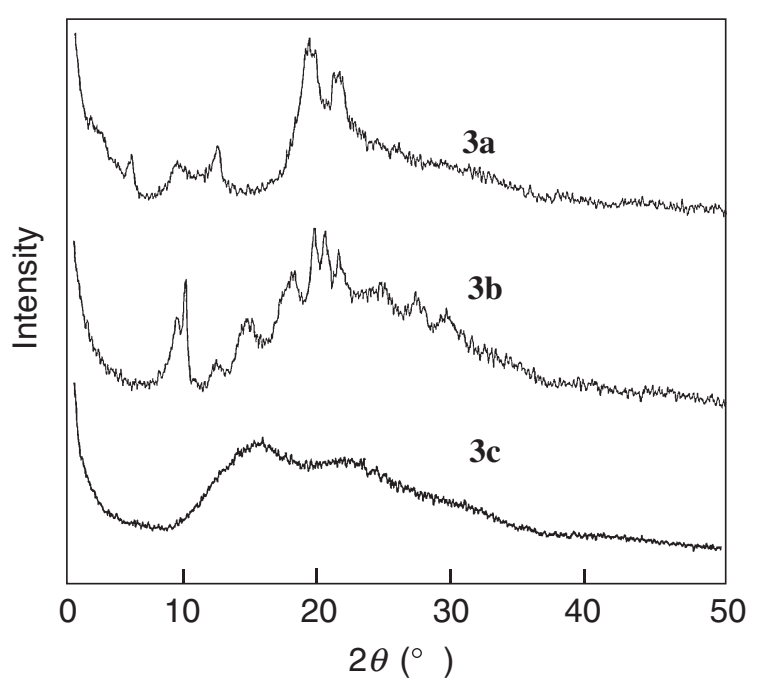

Figure 2. XRD spectra of $\mathbf{3 a}, \mathbf{3 b}$ and $\mathbf{3 c}$.

Table II. As a result, $\mathbf{2 a}$ and $\mathbf{2 b}$, particularly $\mathbf{2 a}$, containing diphenylsilanol groups have good thermal stability compared with $\mathbf{2 c}$ and $\mathbf{2 d}$ containing dimethylsilanol groups.

\section{Characterizations of Polymers}

The XRD patterns of 3a-c are shown in Figure 2. 3d (not shown) was a crystalline polymer, whose XRD pattern coincided with that in the literature. ${ }^{35} \mathbf{3 c}$ was amorphous polymer since this polymer only showed two broad hallows in the wide angle region $(2 \theta=$ $\sim 15^{\circ}$ and $\sim 22^{\circ}$ ). On the other hand, $\mathbf{3 a}$ and $\mathbf{3 b}$ were crystalline polymers because sharp reflection peaks were observed. The reflection peaks became sharp by aging the samples at $160{ }^{\circ} \mathrm{C}$ for $1 \mathrm{~h}$. This fact indicated that crystal growth was accelerated by aging.

\section{Thermal Properties of Polymers}

The DSC curves of $\mathbf{3 a}$ and $\mathbf{3 b}$ were shown in Figure 3. 3a showed two endothermic peaks at 289 and $323{ }^{\circ} \mathrm{C}$. From the optically polarized microscopy, 3a held solid-state at $289^{\circ} \mathrm{C}$ before melting at $328 \pm$ $5^{\circ} \mathrm{C}$. Therefore, $T_{\mathrm{m}}$ of $\mathbf{3 a}$ determined at $323^{\circ} \mathrm{C}$ by DSC measurement, the endothermic peak at $289^{\circ} \mathrm{C}$ would be resulted from crystal-crystal phase transition. 3b showed a broad endothermic peak around at $391{ }^{\circ} \mathrm{C}$ on the first heating scan. This peak would be caused by melting, however, $\mathbf{3 b}$ held solid-state at melting point. In addition, this peak did not be detected on the second heating scan. These results showed that some irreversible reaction, such as cross-linking reaction would occur.

On the other hand, $\mathbf{3 c}$ and $\mathbf{3 d}$ indicated a glass transition at $67^{\circ} \mathrm{C}$ and a melting point at $136^{\circ} \mathrm{C}$, respectively as shown in Table II. Recently, Kawakami et al. also investigated the thermal property of $\mathbf{3 c}$, which exhibited the $T_{\mathrm{g}}$ of $56{ }^{\circ} \mathrm{C} .{ }^{27}$ For $3 \mathbf{c}$, our sample 


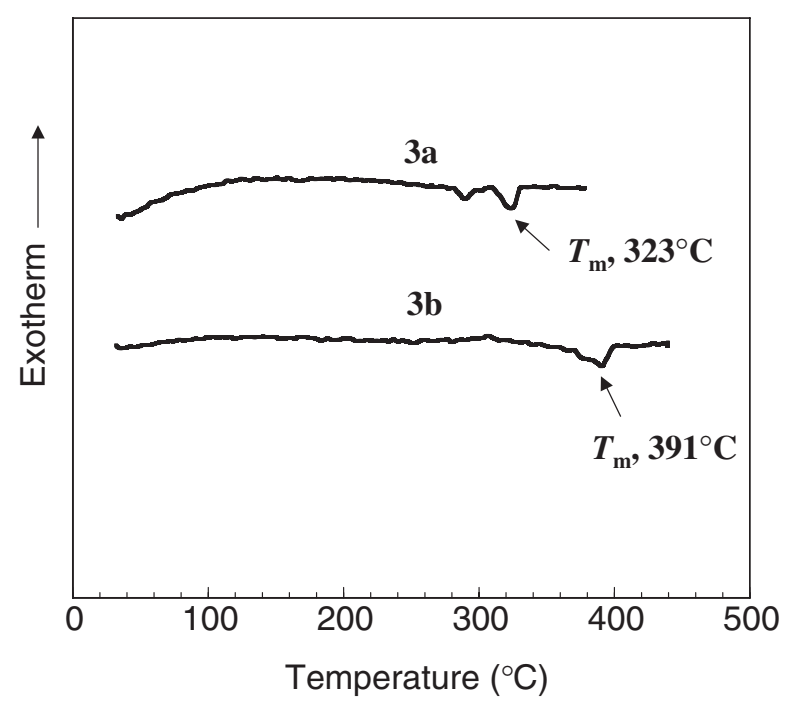

Figure 3. DSC curves of 3a (second heating) and 3b (first heating).

showed slightly higher $T_{\mathrm{g}}$ than their sample in spite of almost the same as the number-average molecular weight. This would result from the different heating rate in DSC measurement, and furthermore the different chemical structures of chain-ends of the polymers should affect the $T_{\mathrm{g}}$ 's because of different methods of polymerizations. The $T_{\mathrm{m}}$ of $\mathbf{3 d}$ was coincided with that in the literature. ${ }^{8}$

It was found that the fully aromatic polysilarylenesiloxane, such as $\mathbf{3 a}$ and $\mathbf{3 b}$, was one of the polymersolids showing the highest $T_{\mathrm{g}}$ and/or $T_{\mathrm{m}}$ in the ever known polysilarylenesiloxanes. ${ }^{25}$ Thus the transformation of side-chain methyl groups to phenyl groups resulted in a significant rise of a $T_{\mathrm{g}}$ or $T_{\mathrm{m}}$ for a polysilarylenesiloxane.

Figure 4 give the TG curves of polymers. 3a showed a good thermal chemical stability in air, and started to decompose from about $500{ }^{\circ} \mathrm{C}$ by two steps (at $\sim 560$ and $\sim 650^{\circ} \mathrm{C}$ ), which corresponded to the third and fourth steps of the weight losses for the monomer 2a (see Figure 1).

3b showed a slight weight loss at about $160-180^{\circ} \mathrm{C}$ $(-0.36 \mathrm{wt} \%)$. This slight weight loss would result from the dehydration between the chain-ends, because no weight loss was observed for $\mathbf{3} \mathbf{b}^{\prime}$ which was obtained to treat $\mathbf{3 b}$ at $180^{\circ} \mathrm{C}$ for $1 \mathrm{~h}$. In addition, the IR spectrum of $\mathbf{3} \mathbf{b}^{\prime}$ also supported the dehydration as that the absorption band arising from $\mathrm{Si}-\mathrm{O}-\mathrm{Si}$ vibration at $1060 \mathrm{~cm}^{-1}$ increased compared with that of 3b. $\mathbf{3} \mathbf{b}^{\prime}$ without this initial loss was thermally stable in the similar to 3a. The large weight losses by two steps in the higher temperature regions of $\mathbf{3} \mathbf{b}$ and $\mathbf{3} \mathbf{b}^{\prime}$ occurred around at 550 and $670^{\circ} \mathrm{C}$, and coincided with that of the monomer $\mathbf{2 b}$ (see Figure 1). The weight loss of $28 \%$ up to $500{ }^{\circ} \mathrm{C}$ for $\mathbf{2 b}$ was too much to dehydrate

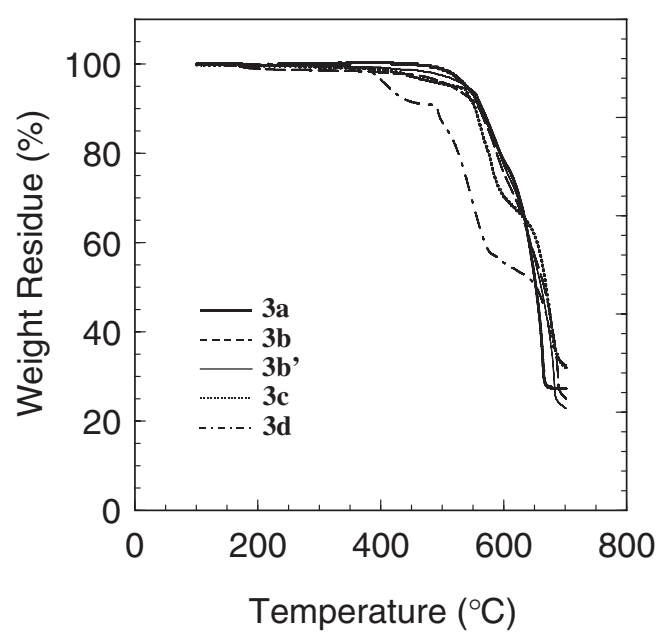

Figure 4. TG curves of polymers at a heating rate of $10^{\circ} \mathrm{C} \mathrm{m^{-1 }}$ under air flow.

among the monomers, as mentioned above. Then $\mathbf{3} \mathbf{b}^{\prime}$ containing less chain-ends, i.e. silanol group was stable below $500^{\circ} \mathrm{C}$. Furthermore, 2a having $p$-disilylphenylene structure did not exhibit such a weight loss. Therefore, it was revealed that the silanol group bonded directly to a $p, p^{\prime}$-biphenylene moiety, such as $\mathbf{2 b}$, easily decomposed in the region of $200-500{ }^{\circ} \mathrm{C}$ in an ordinary atmosphere.

The 3d, whose thermal degradation behavior had been investigated in detail in the past, obviously exhibited three steps of weight loss processes. According to Dvornic et al. ${ }^{22}$ the first step of the thermal degradation at $400^{\circ} \mathrm{C}$ was caused by the splitting off of the methyl groups with formation of crosslinks by oxygen bridges. The second step at $500-600{ }^{\circ} \mathrm{C}$ was done by formations of volatile organosilicone products due to the degradation. And the third step at $700^{\circ} \mathrm{C}$ was done by thermo-oxidative degradation of the remaining organic content. Recently, the thermal degradation behavior of $\mathbf{3 c}$ in nitrogen was reported, ${ }^{27}$ in which 3c showed the $T_{\mathrm{d} 5}$ of $484^{\circ} \mathrm{C}$. 3c was slightly more stable than $\mathbf{3 d}$ in nitrogen. On the other hand, 3c also exhibited three steps of weight losses under an ordinary atmosphere, but the first step of the splitting off of methyl groups was suppressed compared with the case of 3d. The $T_{\mathrm{d} 5}$ of $\mathbf{3 c}$ in this work was $100^{\circ} \mathrm{C}$ higher than that of $\mathbf{3 d}$. It was found that the introduction of a $p, p^{\prime}$-biphenylene moiety into the polysilarylenesiloxane backbone resulted in the increase of the thermal and chemical stability in an air although the silanol group was easily decomposed for the monomer. Interestingly, for thus polysilarylenesiloxane, the thermal stability based on $T_{\mathrm{d} 5}$ was enhanced in air compared with the case in nitrogen.

Consequently, it was revealed that the transformation from dimethylsiloxane units to diphenylsiloxane units contributed to an increase of not only a $T_{\mathrm{g}}$ but 
also a thermal stability (based on $T_{\mathrm{d} 5}$ ), as summarized in Table II. Furthermore it was found that the degree of polymerization, in another word, the amounts of chain-ends of silanol groups significantly affected to the thermal stability of a polymer. However in this stage of our studies, only the two kinds of backbone structures were investigated. Therefore the fully aromatic polysilarylenesiloxanes consisted of other backbone structures should be synthesized in order to reveal their thermal properties.

\section{CONCLUSIONS}

In order to obtain a new type of polysilarylenesiloxanes showing high $T_{\mathrm{g}}$, the fully aromatic polysilarylenesiloxanes were synthesized from the corresponding disilanol monomers, and their thermal properties were investigated by using DSC and TG/DTA.

For the disilanol monomers, those having diphenylsilanol groups (2a, 2b) showed the higher $T_{\mathrm{m}}$ and $T_{\mathrm{d} 5}$ than those having dimethylsilanol groups $(\mathbf{2 c}, \mathbf{2 d})$. Although the degradation behavior of $\mathbf{2 c}$ and $\mathbf{2 d}$ which exhibited the volatility above $T_{\mathrm{m}}$ was not known very well, it was found that the structure of hydroxysilyl substituted biphenylene easily decomposed in comparability of $\mathbf{2 a}$ and $\mathbf{2 b}$. Additionally, an interesting phenomenon was observed, that is, the melt-condensation among fully aromatic disilanol monomers was suggested over the $T_{\mathrm{m}}$. This would be a promising method to form a film of the fully aromatic polysilarylenesiloxanes difficult to dissolve to common solvents. The melt-condensation behavior of the fully aromatic disilanol monomers is being studied in progress, and will be reported soon.

The fully aromatic polysilarylenesiloxanes were obtained by solution polymerization as insoluble powder, and melting points of $\mathbf{3 a}$ and $\mathbf{3 b}$ were 323 and $391{ }^{\circ} \mathrm{C}$, respectively. A cross-linking reaction would occur simultaneously with melting in the case of $\mathbf{3 b}$ therefore $\mathbf{3 b}$ held solid-state at melting point. Then, these polymers introduced tetraphenyldisiloxane units showed good thermally chemical stability in air since no weight loss was observed below $500^{\circ} \mathrm{C}$. In addition, tetraphenyldisiloxane units resulted in an increase of $T_{\mathrm{m}}$ as these units contributed to enhance the rigidity of the polymer-backbone. Finally, it was shown that the fully aromatic polysilarylenesiloxanes are new candidates for the high-temperature resistant materials in this work.

Acknowledgment. We sincerely appreciated to Associate Professor, Dr. Nobukatsu Nemoto, Faculty of Engineering, Nihon University, for very useful discussion with him, and to Mr. Takashi Kawakami, Ebara Corporation, for his technical contribution.

\section{REFERENCES}

1. T. M. Birshtein and O. B. Ptitsyn, "Conformations of Macromolecules," Interscience Publishers, New York, 1966, Chapt. 7.

2. P. J. Flory, "Statistical Mechanics of Chain Molecules," Interscience Publishers, New York, 1969, Chapt. 5.

3. P. R. Dvornic and R. W. Lenz, "High Temperature Siloxane Elastomers," Hüthing \& Wepf, Basel, 1990, Chapt. II.

4. C. C. Currie and B. F. Smith, Ind. Eng. Chem., 42, 2457 (1950).

5. G. Grant 3rd and C. C. Cure, Mech. Eng., 73, 311 (1951).

6. O. B. Young and C. E. Dickerman, Ind. Eng. Chem., 46, 364 (1954).

7. K. Nagai, T. Masuda, T. Nakagawa, B. D. Freeman, and I. Pinnau, Prog. Polym. Sci., 26, 721 (2001).

8. R. L. Merker and M. J. Scott, J. Polym. Sci., A, 2, 15 (1964).

9. N. Okui, H. M. Li, and J. H. Magill, Polymer, 19, 411 (1978).

10. M. Ikeda, T. Nakamura, Y. Nagase, K. Ikeda, and Y. Sekine, J. Polym. Sci., Poly. Chem. Ed., 19, 2595 (1981).

11. R. L. Merker, M. J. Scott, and G. G. Haberland, J. Polym. Sci., A, 2, 31 (1964).

12. W. R. Dunnavant, Inorg. Macromol. Rev., 1, 165 (1971).

13. J. M. Funt, R. D. Parekh, J. H. Magill, and Y. T. Shah, J. Polym. Sci., Polym. Chem. Ed., 13, 2181 (1975).

14. C. U. Pittman. Jr., W. J. Patterson, and S. P. Mcmanus, J. Polym. Sci., Polym. Chem. Ed., 14, 1715 (1976).

15. P. R. Dvornic and R. W. Lenz, J. Polym. Sci., Polym. Chem. Ed., 20, 951 (1982).

16. Y. Nagase, T. Masubuchi, K. Ikeda, and Y. Sekine, Polymer, 22, 1607 (1981).

17. Y. Nagase, K. Ikeda, and Y. Sekine, Polymer, 23, 1646 (1982).

18. Y. Nagase, T. Nakamura, A. Misawa, K. Ikeda, and Y. Sekine, Polymer, 24, 457 (1983).

19. Y. Nagase, T. Fukatsu, K. Ikeda, and Y. Sekine, Polymer, 24, 463 (1983).

20. L. W. Breed, R. L. Elliott, and M. E. Whitehead, J. Polym. Sci., A-1, 5, 2745 (1967).

21. R. E. Burks Jr., E. R. Covington, M. V. Jackson, and J. E. Curry, J. Polym. Sci., Polym. Chem. Ed., 11, 319 (1973).

22. P. R. Dvornic and R. W. Lenz, Polymer, 24, 763 (1983).

23. H. D. Zhu, S. W. Kantor, and W. J. MacKnight, Macromolecules, 31, 850 (1998).

24. P. R. Dvornic, H. J. Perpall, P. C. Uden, and R. W. Lenz, J. Polym. Sci., Polym. Chem. Ed., 27, 3503 (1989).

25. Y. Kawakami, Y. Li, Y. Liu, M. Seino, C. Pakjamsai, M. Oishi, Y. H. Cho, and I. Imae, Macromol. Res., 12, 156 (2004).

26. Y. Li and Y. Kawakami, Macromolecules, 32, 3540 (1999).

27. J. Y. Moon, T. Miura, I. Imae, D. W. Park, and Y. Kawakami, Silicon Chem., 2, 139 (2002).

28. T. Homma, Mater. Sci. Eng., R23, 243 (1998).

29. M. Kohno, J. Photopolym. Sci. Technol., 12, 189 (1999).

30. K. Maex, M. R. Baklanov, D. Shamiryan, F. Lacopi, S. H. Brongersma, and Z. S. Yanovitskaya, J. Appl. Phys., 93, 8793 (2003). 


\section{H. Іто et al.}

31. M. I. Buzin, M. V. Gerasimov, E. S. Obolonkova, and V. S. Papkov, J. Polym. Sci., Part A: Polym. Chem., 35, 1973 (1997).

32. H. N. Beck and R. G. Chaffee, J. Chem. Eng. Data, 8, 602 (1963).
33. L. W. Breed and R. L. Elliott, J. Organomet. Chem., 9, 188 (1967).

34. V. Bažant and M. Černý, Collect. Czech. Chem. Commun., 39, 1728 (1974).

35. N. Okui and J. H. Magill, Polymer, 18, 1152 (1977). 